\title{
Studies on the Codeposition of SiC Nanopowder with Nickel, Cobalt, and Co-Ni Alloys
}

\author{
Ewa Rudnik and Sławomir Syrek \\ Department of Physical Chemistry and Metallurgy of Non-Ferrous Metals, Faculty of Non-Ferrous Metals, \\ AGH University of Science and Technology, Aleja Mickiewicza 30, 30-059 Cracow, Poland
}

Correspondence should be addressed to Ewa Rudnik; erudnik@agh.edu.pl

Received 5 February 2014; Revised 3 July 2014; Accepted 14 July 2014; Published 23 July 2014

Academic Editor: Fahmina Zafar

Copyright (C) 2014 E. Rudnik and S. Syrek. This is an open access article distributed under the Creative Commons Attribution License, which permits unrestricted use, distribution, and reproduction in any medium, provided the original work is properly cited.

\begin{abstract}
Electrodeposition of $\mathrm{SiC}$ nanopowder (approximately $120 \mathrm{~nm}$ ) with nickel, cobalt, and Co-Ni alloy matrix was studied. It was found that particles suspended in the bath affect slightly the reduction of metallic ions. Incorporation of the ceramic particles was governed mainly by the morphology of the matrix surface, while no strict correlation between the amount of cobalt ions adsorbed on the powder and the $\mathrm{SiC}$ content in the composites was found. Microhardness of nickel deposits was $585 \pm 5 \mathrm{HV}$, while for cobalt-rich coatings (84-95 wt.\% Co) the values were in the range of $260-290 \mathrm{HV}$, independently of the SiC content in the coatings. Finegrained nickel deposits were characterized by good corrosion resistance, while cobalt and Co-Ni alloys showed high corrosion current densities.
\end{abstract}

\section{Introduction}

Electrodeposited composite coatings consist of intentionally joined together two or more components (i.e., matrix and reinforcement) with different properties receiving a new unique and macroscopically monolithic material exhibiting desirable, better, or different characteristics in comparison with each individual component or only mixed together. Properties of the composites are determined not only by a kind of matrix (metal or alloy), but also by the type and size of the incorporated particles. Various metal-particle combinations have been developed $[1,2]$. Among them nickel matrix composites seem to be the most investigated systems [1-6], while composite coatings based on cobalt $[1,7-9]$ and Co-Ni alloys [10-13] were studied in a lesser extent. Coatings are reinforced usually with ceramic particles as carbides, oxides, nitrides, borides, and so forth. Such materials show high hardness and strength, but a decrease in the properties at elevated temperatures can occur in some cases [14].

A series of our previous studies on the codeposition of the composites was carried out using micron-sized $\mathrm{SiC}$ particles. The percentage of ceramic phase in the electrodeposited $\mathrm{Ni}$, Co, and Co-Ni alloy matrix composites as well as some properties of the layers determined in the dependence on the powder concentration in the plating bath, current density, and the presence of some additives were reported [1419]. The present paper is focused on understanding the influence of the electrolyte composition and the presence of $\mathrm{SiC}$ nanoparticles in the plating bath on the course of the cathodic reactions as well as composition, morphology, and some properties of the deposits. It is known that behavior of nanoparticles during electrodeposition differs seriously from that observed for the particles with larger sizes $[1,2]$. For example, it was found that increase in the concentration of $\mathrm{SiC}$ microparticles in the bath was accompanied by an increase in the particle's content in the $\mathrm{Ni}$ or $\mathrm{Ni}-\mathrm{Co}$ alloy matrix to a certain constant value $[6,19]$, while for nanoparticles a maximum followed by subsequent strong inhibition of the incorporation was observed [20,21]. However, some literature data show also that other effects and saturation state of particles in the deposits can be reached at high nanoparticle concentration in the suspension [2]. It was also observed that incorporation of very fine particles (approx. $20 \mathrm{~nm}$ ) results in the change of the crystalline structure of the metallic coatings and a decrease in the size of the matrix grains $[2,10]$. It was attributed to the adsorption 
TABLE 1: Composition of the baths.

\begin{tabular}{|c|c|c|c|c|c|}
\hline \multirow{3}{*}{ Component } & \multicolumn{5}{|c|}{ Bath type } \\
\hline & $\mathrm{Co}, \mathrm{Co} / \mathrm{SiC}$ & $\mathrm{Ni}, \mathrm{Ni} / \mathrm{SiC}$ & CoNi-1, CoNi-1/SiC & $\mathrm{CoNi}-2, \mathrm{CoNi}-2 / \mathrm{SiC}$ & $\mathrm{CoNi}-3, \mathrm{CoNi}-3 / \mathrm{SiC}$ \\
\hline & \multicolumn{5}{|c|}{ Concentration, $\mathrm{g} \cdot \mathrm{dm}^{-3}$} \\
\hline $\mathrm{CoSO}_{4} \cdot 7 \mathrm{H}_{2} \mathrm{O}$ & 25 & - & 20 & 12.5 & 5 \\
\hline $\mathrm{CoCl}_{2} \cdot 6 \mathrm{H}_{2} \mathrm{O}$ & 200 & - & 130 & 100 & 70 \\
\hline $\mathrm{NiSO}_{4} \cdot 7 \mathrm{H}_{2} \mathrm{O}$ & - & 25 & 5 & 12.5 & 20 \\
\hline $\mathrm{NiCl}_{2} \cdot 6 \mathrm{H}_{2} \mathrm{O}$ & - & 200 & 70 & 100 & 130 \\
\hline $\mathrm{H}_{3} \mathrm{BO}_{3}$ & 25 & 25 & 25 & 25 & 25 \\
\hline Saccharin & 0.5 & 0.5 & 0.5 & 0.5 & 0.5 \\
\hline $\mathrm{SiC}$ & 5 & 5 & 5 & 5 & 5 \\
\hline $\mathrm{Co}(\mathrm{II}): \mathrm{Ni}(\mathrm{II})$ & - & - & $2: 1$ & $1: 1$ & $1: 2$ \\
\hline
\end{tabular}

of the nanoparticles on the cathode surface and, therefore, increased surface area available for nucleation of metal grains. It is also commonly accepted that adsorption of the metal ions can promote incorporation of the particles into the metal matrix $[1,2,15,19]$, thus affecting the electrophoretic phenomena of nanoparticles as well [1]. Similar phenomenon was observed for cobalt ions in the $\mathrm{Ni}-\mathrm{Co} / \mathrm{Al}_{2} \mathrm{O}_{3}[11]$ and $\mathrm{Ni} / \mathrm{SiC}[13,22]$ systems. Hence, the aim of this work was mainly to determine the factors influencing the amount of the nanosized $\mathrm{SiC}$ particles incorporated into the metallic deposit from the acidic baths of various $\mathrm{Ni}$ (II)/Co(II) concentration ratios.

\section{Experimental}

Metallic and composite coatings were electrodeposited from the sulphate-chloride solutions of various $\mathrm{Co}(\mathrm{II}): \mathrm{Ni}$ (II) ions concentration ratios $(2: 1,1: 1$, and $1: 2)$. SiC nanopowder (Sigma-Aldrich) with an average grain diameter of 110$130 \mathrm{~nm}$ was used. $\mathrm{pH}$ of the solutions was 4.4. Detailed composition of the baths is presented in Table 1. Electrolysis was carried out at room temperature in a cuboid vessel containing $0.4 \mathrm{dm}^{3}$ of the electrolyte. Three electrodes were hung vertically and parallel to each other. Copper plate $\left(18 \mathrm{~cm}^{2}\right)$ as the cathode substrate and a couple of nickel and/or cobalt anodes were used. Copper substrates were polished in the mixture of concentrated acids $\left(\mathrm{HNO}_{3}: \mathrm{CH}_{3} \mathrm{COOH}: \mathrm{H}_{3} \mathrm{PO}_{4}\right.$ in $1: 1: 2$ volume ratio) for $90 \mathrm{~s}$ at room temperature, rinsed with deionized water and acetone, and dried. After deposition, all samples were washed in deionized water and then in acetone using ultrasonic cleaner (each step for $5 \mathrm{~min}$.). The electrolytic bath was agitated with a magnetic stirrer with a rotation rate of $630 \mathrm{rpm}$. For the composite preparation, suspension was additionally agitated for $45 \mathrm{~min}$. before each experiment to preserve sedimentation of the powder in the electrolytic cell. The metallic and composite layers were deposited at the constant current density of $1 \mathrm{~A} \cdot \mathrm{dm}^{-2}$ for $120 \mathrm{~min}$. A copper coulometer was used for determination of the total charge flowing through the electric circuit.

Cathodic polarization curves were registered under potentiodynamic conditions. Linear sweep voltammetry (LSV) was realized from open circuit potential (OCP) to $-1000 \mathrm{mV}$ versus saturated calomel electrode (SCE) at a sweep rate of $10 \mathrm{mV} \cdot \mathrm{s}^{-1}$ (Atlas Sollich EII Potentiostat). Prior to each measurement, a metallic layer was electrodeposited for $30 \mathrm{~min}$. at the current density of $1 \mathrm{~A} \cdot \mathrm{dm}^{-2}$.

Composition of the deposits was determined using EDS analysis, while morphology of the coatings was observed using SEM (Hitachi S4700) and AFM (Integra Aura) microscopes. Pure metals were also analyzed by means of TEM microscope (JEM 2010ARP). Vickers hardness of the deposits was measured on the surface of the samples with a microhardness method at the load of $50 \mathrm{~g}$ (PMT-3). Corrosion resistance of the coatings was determined in $10 \% \mathrm{H}_{2} \mathrm{SO}_{4}$ at room temperature. LSV curves were registered from $-1000 \mathrm{mV}$ to $500 \mathrm{mV}(\mathrm{SCE})$ at the potential scan rate of $10 \mathrm{mV} \cdot \mathrm{s}^{-1}$.

Adsorption of $\mathrm{Ni}(\mathrm{II})$ and $\mathrm{Co}(\mathrm{II})$ ions was determined in diluted $(1: 100)$ working baths $(\mathrm{pH} 4.4)$. Solution samples of $50 \mathrm{~cm}^{3}$ were mixed with $0.2 \mathrm{~g}$ of the $\mathrm{SiC}$ powder in all experiments. After $120 \mathrm{~min}$., SiC particles were centrifuged and final $\mathrm{Ni}$ (II) and $\mathrm{Co}$ (II) concentrations were determined by means of atomic absorption spectroscopy (Perkin Elmer Atomic Absorption Spectrometer 3110).

Potential zeta of the $\mathrm{SiC}$ powder was determined in $1 \mathrm{mM}$ $\mathrm{NaCl}$ solutions of the $\mathrm{pH}$ from the range from 2 to 6 (adjusted with $0.05 \mathrm{M} \mathrm{HCl}$ ). Measurements were performed at room temperature using "Zetasizer Nano" apparatus.

In all experiments $\mathrm{SiC}$ particles were used as received, without any former cleaning procedure.

\section{Results and Discussion}

3.1. Electrochemical Studies. The cathodic polarization curves for $\mathrm{Ni}, \mathrm{Co}$, and $\mathrm{Co}-\mathrm{Ni}$ alloys as well as composites were determined in potentiodynamic conditions (Figure 1). It was observed that electrodeposition was accompanied by high polarization of the electrode and the process started usually at overpotentials reaching more than $250 \mathrm{mV}$. For two cases, Co and $\mathrm{CoNi}-3$ alloy deposition, the presence of $\mathrm{SiC}$ particles in the bath seemed to have no effect on the course of the polarization curves. For other systems, increase in the cathodic polarization by the carbide nanoparticles was observed.

The most inhibited process was reduction of nickel ions for both pure matrix and composite deposition. The rate of the cathodic reaction registered during nickel deposition at the potential of $-1000 \mathrm{mV}$ (SCE) corresponded to a current 


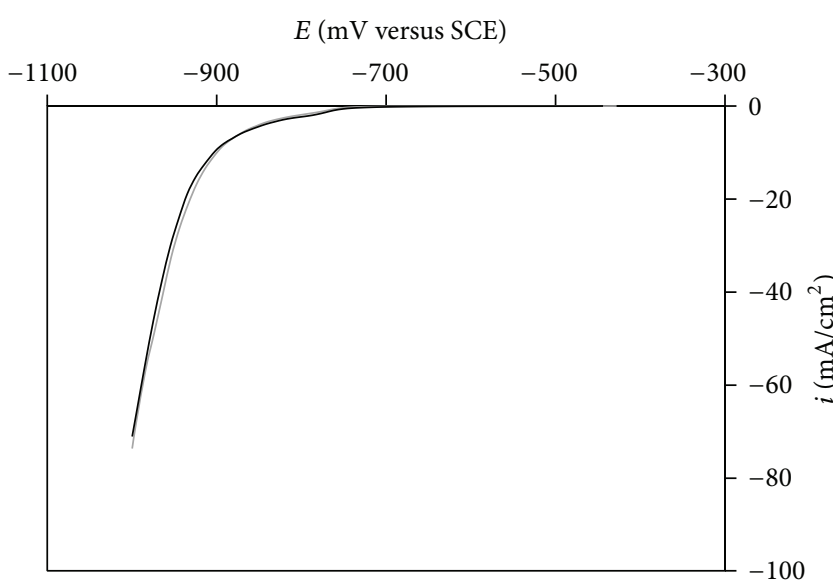

- Co

- $\mathrm{Co}-\mathrm{SiC}$

(a)

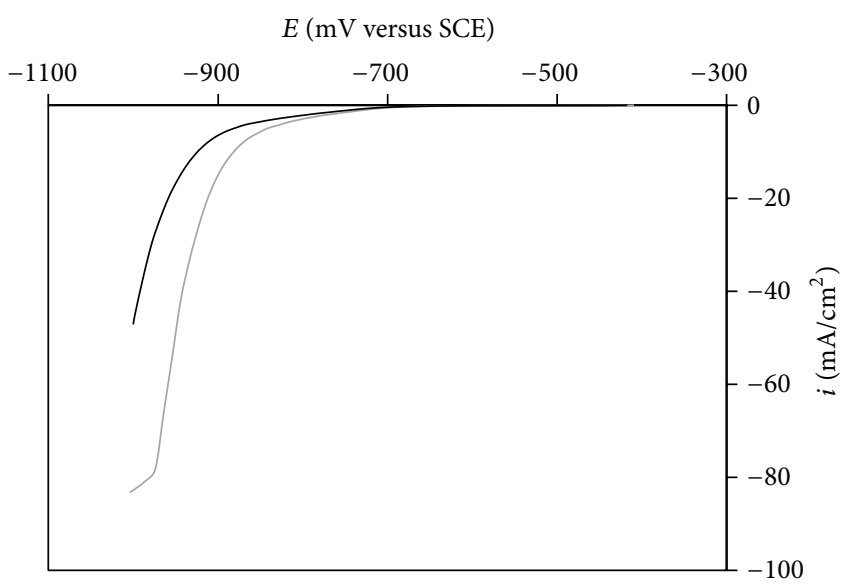

- CoNi 1

- CoNi 1-SiC

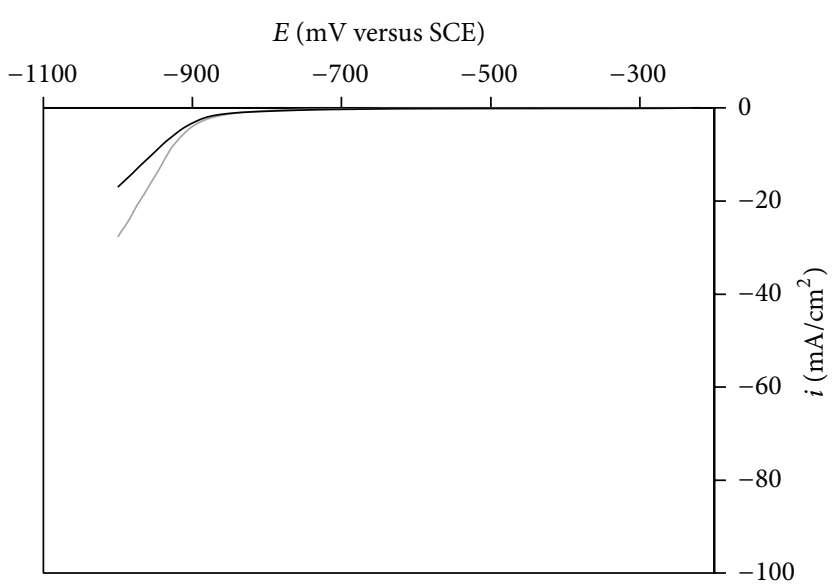

$\mathrm{Ni}$

- Ni-SiC

(b)

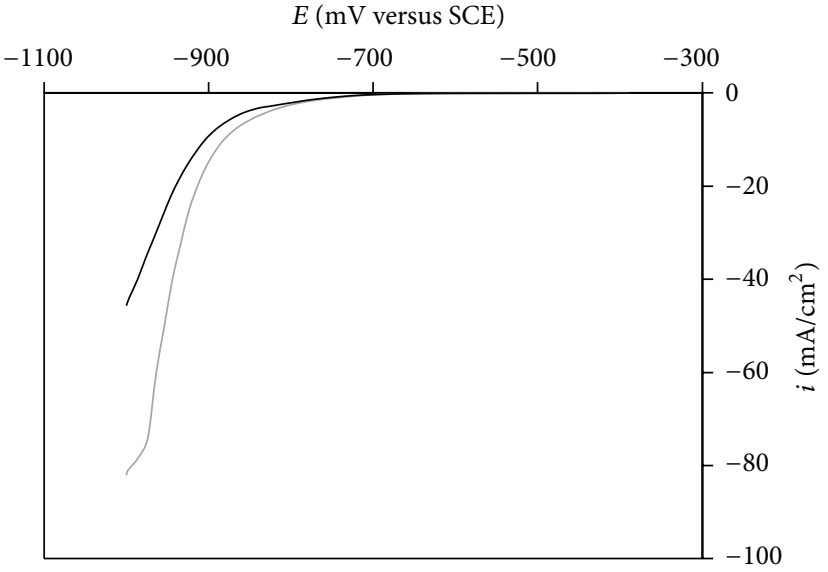

(d)

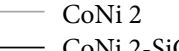

- CoNi 2-SiC

(c)

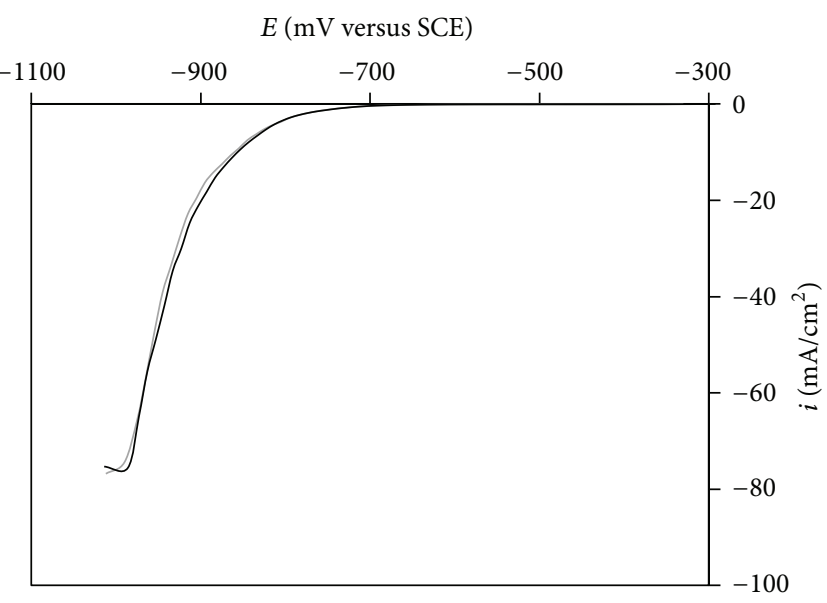

CoNi 3

- $\mathrm{CoNi} 3-\mathrm{SiC}$

(e)

FIGURE 1: The influence of the electrolyte composition and $\mathrm{SiC}$ presence on the cathodic polarization curves. 
TABLE 2: Stationary cathode potential (OCP).

\begin{tabular}{lccc}
\hline Sample & OCP, mV (SCE) & Sample & OCP, mV (SCE) \\
\hline Co & -428 & $\mathrm{Co} / \mathrm{SiC}$ & -444 \\
$\mathrm{Ni}$ & -221 & $\mathrm{Ni} / \mathrm{SiC}$ & -230 \\
$\mathrm{CoNi}-1$ & -409 & $\mathrm{CoNi}-1 / \mathrm{SiC}$ & -417 \\
$\mathrm{CoNi}-2$ & -389 & $\mathrm{CoNi}-2 / \mathrm{SiC}$ & -379 \\
$\mathrm{CoNi}-3$ & -330 & $\mathrm{CoNi}-3 / \mathrm{SiC}$ & -292 \\
\hline
\end{tabular}

density of approximately $25 \mathrm{~mA} \cdot \mathrm{cm}^{-2}$ while in the solutions containing cobalt ions of the same concentration a current density of about $70 \mathrm{~mA} \cdot \mathrm{cm}^{-2}$ was found. Gradual increase in cobalt ions concentration in the nickel baths enhanced the cathodic reaction (alloy deposition) in comparison with the deposition of pure components, despite having the same level of the total concentration of the electroactive ions.

In the $\mathrm{SiC}$ suspensions, the highest cathodic currents were observed for $\mathrm{CoNi}-3 / \mathrm{SiC}$ composite deposition, while increase in the cobalt ions percentage in the suspensions led to a gradual inhibition of the electrode reactions.

Similar influence of cobalt ions on the course of the cathodic polarization curves was observed for other Co-Ni alloy matrix composites [11, 13], independently of $\mathrm{Co}(\mathrm{II}) / \mathrm{Ni}$ (II) concentration ratio in the solution but for nickel content higher than that of cobalt. However, at increased level of cobalt ions concentration in the bath, addition of nickel ions practically did not change the polarization behavior in the $\mathrm{Co}-\mathrm{Ni} / \mathrm{Al}_{2} \mathrm{O}_{3}$ system [11].

In all cases increasing concentration of nickel ions shifted stationary electrode potential (at $i=0$ ) towards more positive values, which was in accordance with the positions of the metals in the electrochemical series (Table 2). The results obtained for $\mathrm{Co} / \mathrm{Co}$ (II) and $\mathrm{Ni} / \mathrm{Ni}$ (II) electrodes were compared with the equilibrium potentials calculated according to the Nernst equation. Obtained potentials were $-522 \mathrm{mV}$ and $-501 \mathrm{mV}$ versus SCE for cobalt and nickel electrode, respectively. They were lower than the experimental values and hence it was concluded that OCP potentials corresponded to the corrosion potentials of both metals.

Detailed analysis of the electrochemical data demonstrated that polarization curves of single metals plotted in the Tafel-type coordinate system (not shown) represented linear dependencies of the overpotential on the logarithm of the current density $(\eta=a+b \log i)$ for currents up to approximately $50-90 i \mathrm{~mA} \cdot \mathrm{cm}^{-2}$ (i.e., to $-980 \mathrm{mV}$ versus SCE). It shows that charge transfer was a rate-controlling stage of the metal ions reduction. However, the slopes of the straight lines differed significantly from the theoretical value ( $59 \mathrm{mV} \cdot \mathrm{dec}^{-1}$ for $\alpha=0.5$ ) and for cobalt and nickel electrodes were equal to $120 \mathrm{mV} \cdot \mathrm{dec}^{-1}$ and $91 \mathrm{mV} \cdot \mathrm{dec}^{-1}$, respectively. For the composites, the respective slopes were higher. However, it should be noted that deposition of nickel and cobalt is accompanied by hydrogen coevolution; hence the slopes determined in the experiment cannot be strictly compared to the theoretical ones. Additionally, the presence of the ceramic particles adsorbed on the electrode surface can affect the cathodic reactions changing the effective area of the working
TABLE 3: Cathodic current efficiency and composition of the deposits.

\begin{tabular}{lcccc}
\hline \multirow{2}{*}{ Sample } & \multirow{2}{*}{ Current efficiency, $\%$} & \multicolumn{3}{c}{ Composition, wt.\% } \\
& & $\mathrm{Co}$ & $\mathrm{Ni}$ & $\mathrm{SiC}$ \\
\hline $\mathrm{Co}$ & $98.4 \pm 0.1$ & 100 & - & - \\
$\mathrm{Co} / \mathrm{SiC}$ & $98.6 \pm 0.0$ & 99.53 & - & 0.47 \\
$\mathrm{Ni}$ & $94.0 \pm 0.1$ & - & 100 & - \\
$\mathrm{Ni} / \mathrm{SiC}$ & $95.1 \pm 0.3$ & - & 99.97 & 0.03 \\
$\mathrm{CoNi}-1$ & $96.3 \pm 0.1$ & 95.05 & 4.95 & - \\
$\mathrm{CoNi}-1 / \mathrm{SiC}$ & $95.7 \pm 0.1$ & 94.40 & 5.20 & 0.40 \\
$\mathrm{CoNi}-2$ & $94.7 \pm 0.0$ & 91.07 & 8.93 & - \\
$\mathrm{CoNi}-2 / \mathrm{SiC}$ & $95.3 \pm 0.1$ & 89.80 & 10.06 & 0.14 \\
$\mathrm{CoNi}-3$ & $93.8 \pm 0.0$ & 85.08 & 14.92 & - \\
$\mathrm{CoNi}-3 / \mathrm{SiC}$ & $94.8 \pm 1.0$ & 83.95 & 15.87 & 0.18 \\
\hline
\end{tabular}

electrode [2]. Similar considerations of the alloy cathodic polarization curves are less valuable since the Tafel equation is derived for single electrode reaction, while two or three cathodic processes can occur during the alloy plating.

3.2. Galvanostatic Electrodeposition. Coatings were deposited at a constant current density. During electrolysis potential of the cathode was registered. It was maintained at constant levels from the range of $-820--920 \mathrm{mV}$ (SCE), depending on the bath composition. It suggests that the cathodic process runs under charge-transfer control, which was in accordance with the previous LSV results.

Table 3 shows the dependence of the current efficiency on the composition of the deposits. $\mathrm{SiC}$ contents in the composites were accounted in the calculations, since only nickel and cobalt ions were reduced on the cathode, while ceramic particles were only mechanically entrapped by the growing metallic layer:

$$
\eta=\frac{m_{M}}{m_{M, t}} \cdot 100 \%=\frac{m_{M / \mathrm{SiC}}-m_{\mathrm{SiC}}}{m_{M, t}} \cdot 100 \%,
$$

where $\eta$ is current efficiency and $m_{M / \mathrm{SiC}}, m_{M}$, and $m_{\mathrm{SiC}}$ are mass of the composite, matrix, and $\mathrm{SiC}$ in the composite, respectively. Mass of the compositewas determined gravimetrically, while mass of $\mathrm{SiC}$ incorporated was calculated according to the weight content of the particles in the deposit. Theoretical mass of the matrix $m_{M, t}$ was found from the following formula:

$$
m_{M, t}=\frac{100 \% \cdot Q}{2 F\left((\% \mathrm{Co}) / M_{\mathrm{Co}}+(\% \mathrm{Ni}) / M_{\mathrm{Ni}}\right)},
$$

where $Q$ is total charge flowed through the circuit during electrolysis (determined colorimetrically); \%Co and \% Ni are percentages of cobalt and nickel in the deposit; $M_{\mathrm{Co}}$ and $M_{\mathrm{Ni}}$ are molar mass of cobalt and nickel, respectively.

The results confirmed the high efficiency of the cathodic processes, since values exceeding $93 \%$ were achieved. The highest current efficiencies were obtained for the electrolytes containing higher amounts of the cobalt ions. In general, 
addition of the $\mathrm{SiC}$ particles to the bath had a positive effect on the current efficiency, although the improvement of the deposition was not high. Cathodic efficiencies were consistent with conclusions drawn from the course of the cathodic polarization curves (Figure 1). Increase in the cathodic polarization corresponds to the lower rate of the process carried out at the constant current density. This is especially visible for electrodeposition of pure metals.

Table 3 shows also composition of the alloys and composites. It was observed that despite the various $\mathrm{Ni}(\mathrm{II}): \mathrm{Co}$ (II) concentration ratios in the baths, cobalt-rich alloys were obtained. It shows that anomalous codeposition exists in the Co-Ni system, where less noble metal (here, cobalt) is deposited preferentially and its percentage in the coatings is higher (85-95wt.\%) than in the bath (33-66 wt.\%). It is a known phenomenon, since anomalous alloy deposition is characteristic of the iron-group metals $(\mathrm{Co}, \mathrm{Ni}$, and $\mathrm{Fe})$ $[11,23]$.

The presence of SiC particles did not change the composition of the matrix. Carbide nanoparticles were built into the deposits in very small amounts (less than $0.5 \mathrm{wt} . \%)$. The highest $\mathrm{SiC}$ content was observed in the $\mathrm{Co} / \mathrm{SiC}$ coating $(0.47 \mathrm{wt} . \%)$, while the smallest was in the $\mathrm{Ni} / \mathrm{SiC}$ layer (0.03wt.\%). The increasing content of cobalt ions in the electrolyte improved incorporation of the ceramic phase.

Yang et al. [13] reported that the presence of $\mathrm{Co}(\mathrm{II})$ $(0.05 \mathrm{M})$ in the nickel sulphate solution promotes $\beta$-SiC codeposition. It was attributed to the strong adsorption of $\mathrm{Co}(\mathrm{II})$ ions on the ceramic particles, which increased the electrostatic attraction between the particle and electrode. $\mathrm{Wu}$ et al. [11] presented a similar view for $\mathrm{Co}-\mathrm{Ni} / \mathrm{Al}_{2} \mathrm{O}_{3}$ system. Wang and Wei [22] observed that addition of small amounts $\left(10^{-5} \mathrm{M}\right)$ of $\mathrm{Na}_{3} \mathrm{Co}\left(\mathrm{NO}_{3}\right)_{6}$ acted as a codeposition catalyst of ultra-fined $\mathrm{SiC}$ particles into the nickel matrix. It was suggested that complex of trivalent cobalt can adsorb on the top of $\mathrm{Ni}(\mathrm{II})$ cation adsorbed on the ceramic particle and may neutralize the particle charge, thus decreasing the surface potential of $\mathrm{SiC}$ particles and enhancing the van der Waals attractive force between adsorbed particle and cathode.

In order to clarify the effect of $\mathrm{Co}(\mathrm{II})$ ions on the codeposition of the $\mathrm{SiC}$ nanoparticles with the metals and $\mathrm{Co}-\mathrm{Ni}$ alloys, some surface properties of $\mathrm{SiC}$ particles (zeta potential and adsorption properties) and morphology of the deposits were investigated. Obtained results are presented in the next sections.

3.3. Surface Properties of SiC Nanoparticles. Codeposition of the ceramic phase with metallic matrix during the cathodic process is dependent on the particle surface charge $[1,2]$. It is commonly accepted that positive surface charge of the particles facilitates their incorporation due to electrostatic attraction of the particles to the negative electrode. It is known that ceramic particles are characterized by a surface charge resulting from the presence of some functional groups as well as adsorbed metal and hydrogen ions $[1,4,11,16,24]$. It is assumed that $\mathrm{SiC}$ particles are covered with hydroxyl, carboxyl, phenolic, and lactonic superficial species, which can dissociate (acidic groups) or associate (basic groups) hydrogen ions from the aqueous solution. It is accompanied

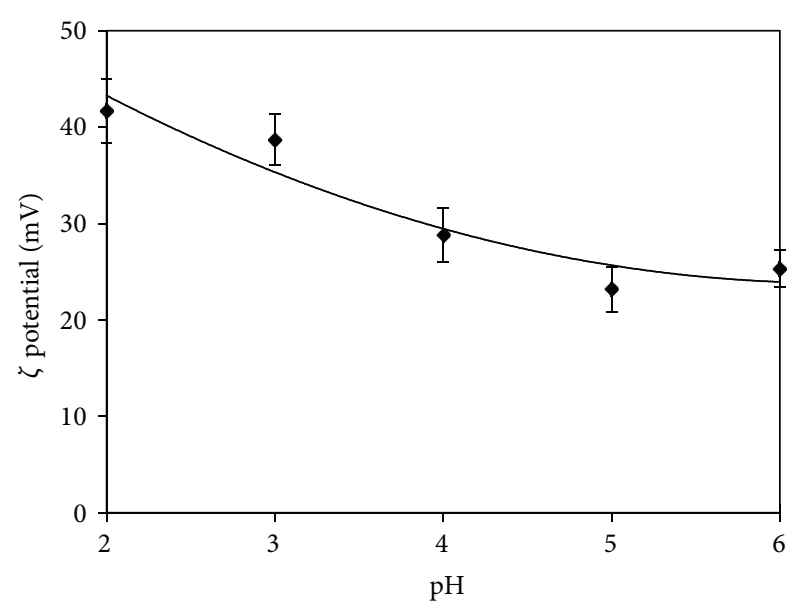

FIGURE 2: Dependence of $\zeta$ potential of $\mathrm{SiC}$ nanopowder on solution $\mathrm{pH}(1 \mathrm{mM} \mathrm{NaCl})$.

by the formation of negatively $\left(\mathrm{S}^{-} \mathrm{O}^{-}\right)$or positively ( $\mathrm{S}-$ $\mathrm{OH}_{2}{ }^{+}$) charged sites, depending on the electrolyte $\mathrm{pH}$ and concentration (ionic strength) [24].

Sign of the particle's surface charge can be deduced from the measurements of the electrokinetic potential (zeta potential). It is a parameter characterizing electric properties of interfacial layers in dispersions and thus affects their stability. Figure 2 shows the effect of $\mathrm{pH}$ ( $\mathrm{NaCl}$ solutions) on the $\zeta$ potential of the $\mathrm{SiC}$ powder used in this study. The $\zeta$ potentials were positive in the whole $\mathrm{pH}$ range studied, although the values decreased with increased alkalization of the electrolyte. Zeta potentials reached $+42-+27 \mathrm{mV}$ in the chloride solution. It corresponds to the moderate stability of the suspension [25] and may potentially improve incorporation of the particles into the growing metal layer. However, composite codeposition was carried out in more concentrated chloride-sulphate baths. It modifies the surface charge of the ceramic particles. Usually, decrease in the $\zeta$ potential is observed in more concentrated solutions $[1,25]$, but the general tendency of the changes with increased $\mathrm{pH}$ remains the same $[4,26]$.

The sign and value of the surface charge are dependent on the amount of ions adsorbed from the electrolyte, since additional competitive processes on the particles surface can occur. Wu et al. [27] reported that somewhat more positive zeta potentials of alumina particles were obtained with increased $\mathrm{Co}(\mathrm{II})$ and $\mathrm{Ni}(\mathrm{II})$ ions concentrations in diluted sulphamate solutions ( $\mathrm{pH}$ 4.0) and these were higher for cobalt bath than for nickel. Moreover, increased fraction of cobalt ions in the cobalt-nickel solutions (total concentrations of metal ions were kept constant) was accompanied by additional rise of the particle's $\zeta$ potential. It corresponded to improved current efficiency of the composite electrodeposition and percentage of incorporated $\mathrm{Al}_{2} \mathrm{O}_{3}$ into the $\mathrm{Co}-\mathrm{Ni}$ alloy matrix. Authors concluded that cobalt ions can readily adsorb on the alumina surface increasing the positive surface charge of the particles and thus enhancing codeposition.

Our previous studies on adsorption of $\mathrm{Co}(\mathrm{II})$ and $\mathrm{Ni}(\mathrm{II})$ ions (separately) on micron-sized $\mathrm{SiC}$ powder confirm that 


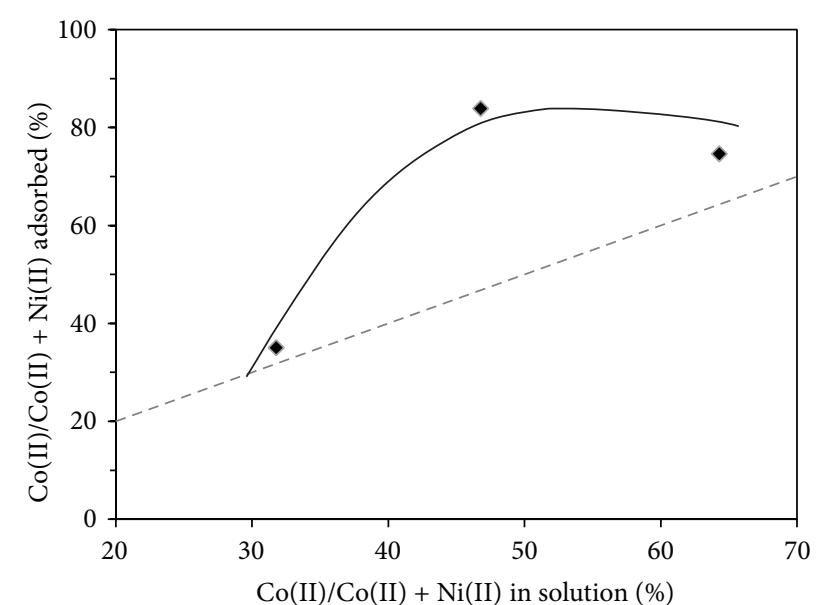

FIgure 3: Effect of the $\mathrm{Co}(\mathrm{II})$ content in the bath on the Co(II) adsorption on $\mathrm{SiC}$ powder.

cobalt ions can adsorb more easily than nickel ions [19]. Figure 3 shows the influence of Co(II) ions percentage in the solution (in diluted working baths) on the adsorption of the ions on $\mathrm{SiC}$ nanopowder. Adsorption of $\mathrm{Co}$ (II) and $\mathrm{Ni}(\mathrm{II})$ occurred as competitive processes in the same system. It was found that adsorption was more efficient in the solutions containing solely ions of one metal. In the case of the simultaneous presence of both metal ions in the electrolyte, the adsorption was somewhat lower (total amount of adsorbed ions was practically the same in all binary baths, that is, approximately $2.4 \mathrm{mg} \cdot \mathrm{g}^{-1} \mathrm{SiC}$ ), but it was not strictly proportional to the concentrations of $\mathrm{Co}$ (II) and $\mathrm{Ni}$ (II) in the solutions.

Comparison of the data presented in Table 3 and Figure 3 suggests that the presence of cobalt ions can enhance the incorporation of particles into the Co-Ni alloy matrix. However, despite the high adsorption of $\mathrm{Ni}(\mathrm{II})\left(6 \mathrm{mg} \cdot \mathrm{g}^{-1} \mathrm{SiC}\right)$ ions on the $\mathrm{SiC}$ particles their content in the $\mathrm{Ni} / \mathrm{SiC}$ composite was the smallest. Ions adsorbed on $\mathrm{SiC}$ can ensure electrostatic attraction between the particles and the cathode, but only reduction of such metallic ions guarantees permanent and stable particle inclusion. It is seriously dependent on the current density and hydrodynamic conditions, which in turn determine the time of the particles attachment to the cathode surface that must be sufficient to their incorporation. The present study indicates that the codeposition of the particles is determined also by some other factors, not only by the surface properties of $\mathrm{SiC}$ nanopowder.

3.4. Morphology of the Deposits. Microscopic observations of as-plated surfaces of the deposits showed that the presence of cobalt favors development of the surface roughness (Figures 4 and 5). Nickel films were characterized by very even surface. High surface smoothness was not advantageous for entrapment of the nanoparticles. The presence of ceramic powder in the $\mathrm{Ni} / \mathrm{SiC}$ composite coatings was detected only by means of the AFM microscope, which allowed analyzing the surface morphology at very high magnifications (Figure 6).
Opposite effects were found for cobalt containing deposits. Figures 4 and 5 show that surfaces of cobalt, Co$\mathrm{Ni}$ alloys, and corresponding composites were characterized by irregular profiles with needle-like and branched grains characteristic of hexagonal crystal structure of cobalt and rich-cobalt solid solutions (Figure 7). The presence of nickel (up to 15\%) and small amounts of dispersed SiC phase did not affect the morphology of the matrix.

Detailed observations of the composite coatings revealed that ceramic nanoparticles were incorporated mainly via mechanical entrapment in the surface irregularities. Hence, higher contents of $\mathrm{SiC}$ were found in the cobalt containing coatings. It was also found that the $\mathrm{SiC}$ particles showed tendency to incorporation into the metallic matrix as the agglomerates.

3.5. Microhardness of the Deposits. Figure 8 shows the microhardness of the electrodeposited coatings. For comparison result of the copper substrate was also presented. In all cases, the metallic layers improved the hardness of the substrate. It was obvious since copper is relatively "soft" metal in comparison with nickel or cobalt. Microhardness of nickel layers was the highest $(570-580 \mathrm{HV})$, while all deposits containing cobalt showed much lower, but similar, values of the microhardness (HV 260-290), independently of the nickel content. This was due to the different crystallographic structures of cobalt and nickel as well as the different sizes of the matrix grains. AFM observations showed that size of the nickel crystallites was about $20-30 \mathrm{~nm}$ (deposition of nickel was accompanied by the largest electrode polarization), while the grains of the cobalt-containing layers were of one micrometer (Figure 9). The presence of SiC did not affect the mechanical properties of the matrix, since the percentages of the built ceramic phase were very low.

Obtained results are consistent with the data for cobaltrich $\mathrm{Co}-\mathrm{Ni} / \mathrm{SiC}$ composites. Srivastava et al. [10] reported no improvement in the hardness for nano-SiC powder reinforced Co-Ni composites (68\% Co) and the corresponding alloy (approximately $300 \mathrm{HV}$ ) despite the fact that change in the morphology of the deposits was observed. It is also worth noting that hardening effect of cobalt is observed mainly for nickel-rich Co-Ni alloys and composites due to gradual change of the morphology, crystalline structure, and refining of the grains of the matrix [11-13].

3.6. Corrosion Resistance of the Deposits. Corrosion resistance of the electrodeposited coatings was determined from the course of the polarization curves registered in $\mathrm{H}_{2} \mathrm{SO}_{4}$ solution. For this purpose, linear sweep voltammetric curves were recorded in the potential range from $-1000 \mathrm{mV}$ to $500 \mathrm{mV}$. The results were plotted in the $\log i-E$ coordinate system. Extrapolation of linear parts of the cathodic and anodic branches to the intersection point allowed determination of corrosion current densities and corrosion potentials. Figure 10 shows the obtained results.

The lowest corrosion current densities were found for nickel layers. It was due to the high smoothness of the coating and very fine-grained structure. Pure cobalt films were characterized by the lowest corrosion resistance, which 

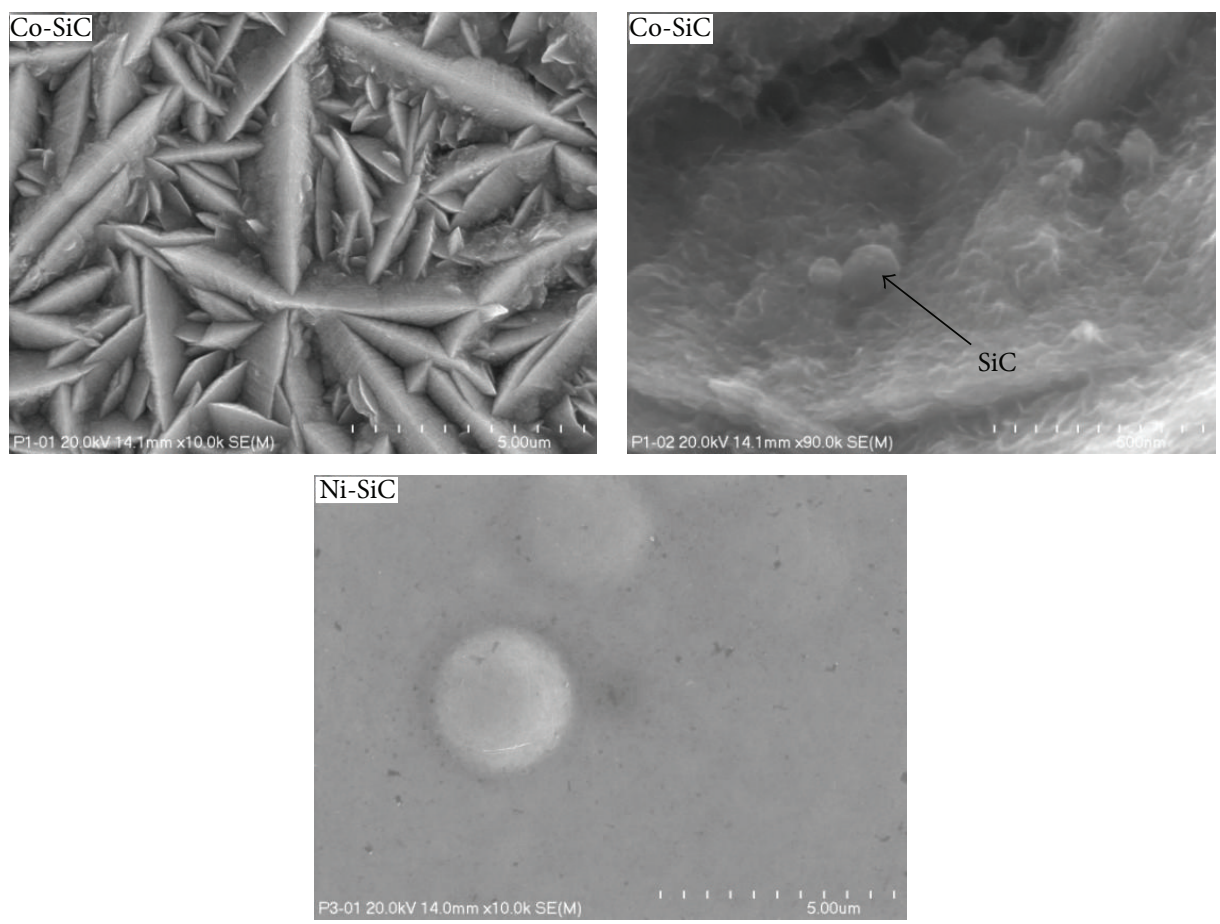

FIGURE 4: SEM micrographs of cobalt and nickel composites.
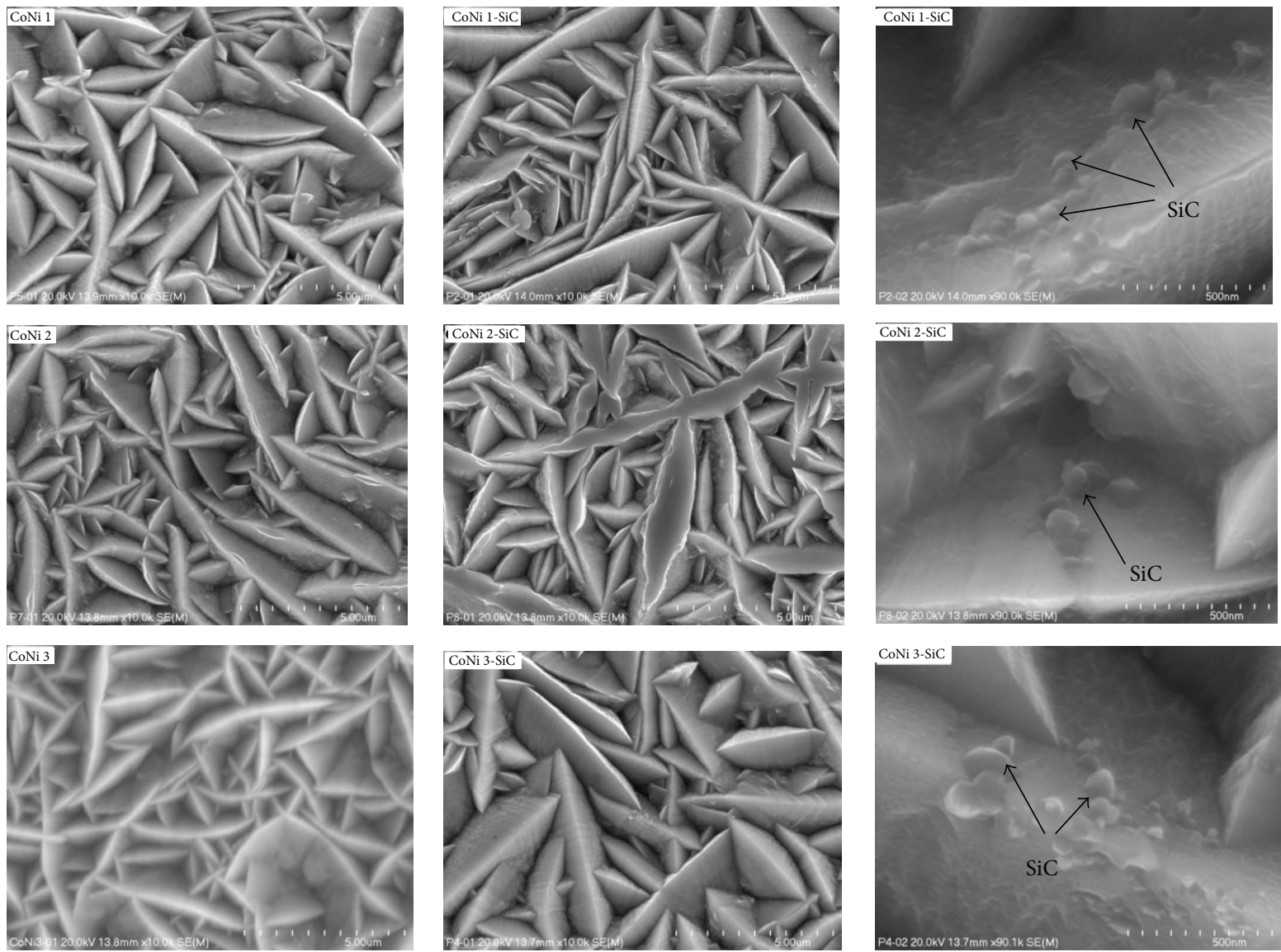

FIGURE 5: SEM micrographs of Co-Ni alloys and composites. 

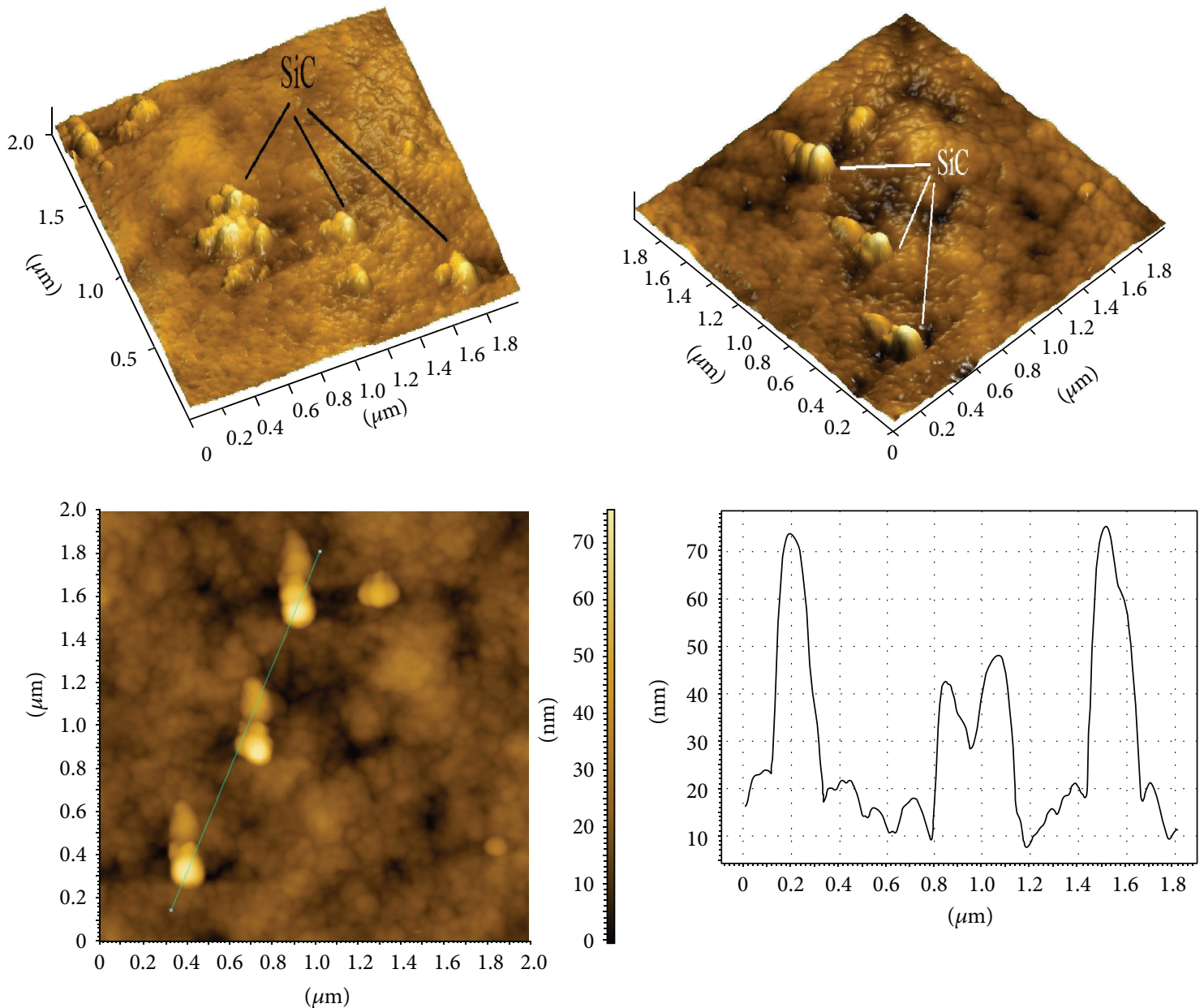

FIgURE 6: AFM micrographs of $\mathrm{Ni} / \mathrm{SiC}$ composite surface.

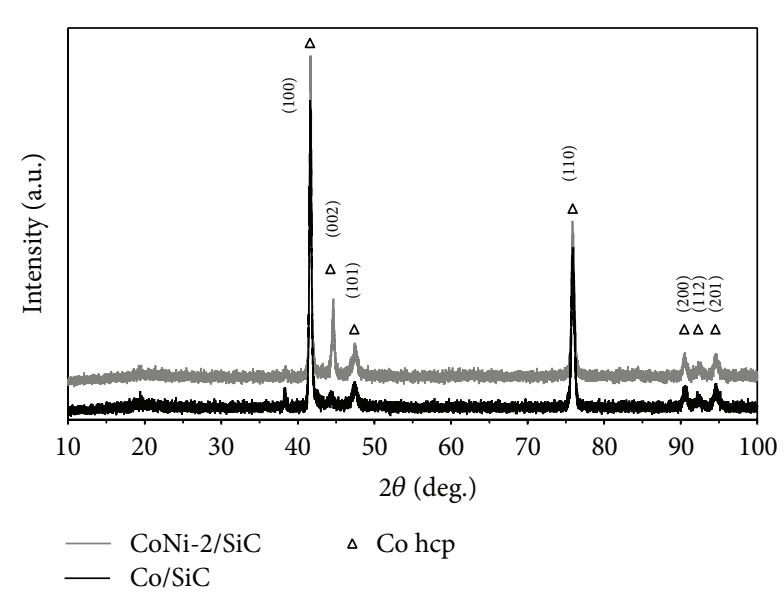

Figure 7: X-ray diffraction patterns of cobalt and CoNi-2 composites.

resulted from the high roughness of the surface (higher actual surface available for electrochemical reactions). The presence of nickel in the alloys improved corrosion resistance of the deposits, despite the significant development of their surface. $\mathrm{SiC}$ particles practically did not improve the anticorrosion

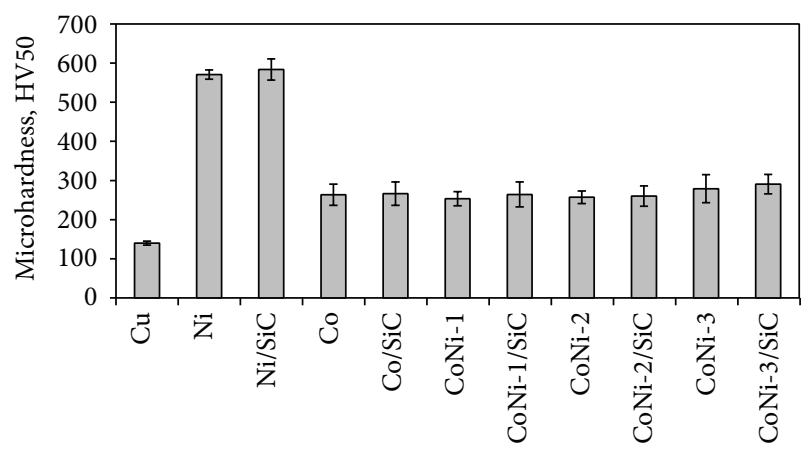

Figure 8: Microhardness of the metallic layers and composite coatings.

properties of the metallic coatings. This was probably associated with the formation of galvanic microcells of metal$\mathrm{SiC}$ (semiconductor), which may enhance dissolution of the metal matrix.

\section{Conclusions}

Electrodeposition of $\mathrm{SiC}$ nanopowder with nickel, cobalt, and alloy matrix was studied. It was found that particles 


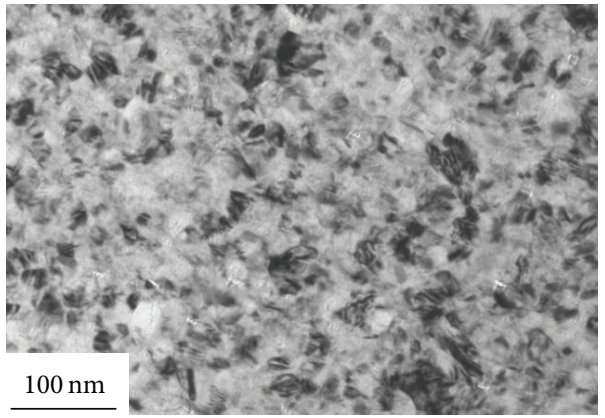

(a)

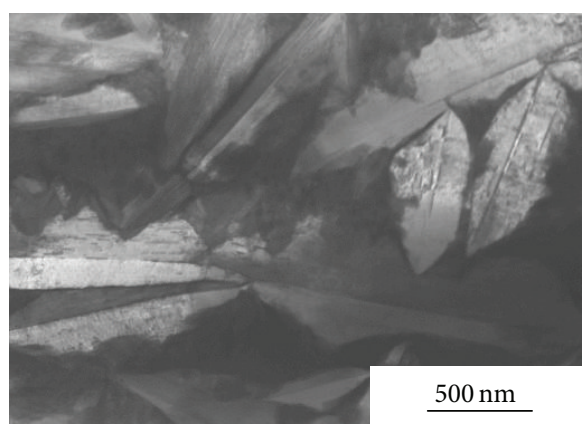

(b)

FIGURE 9: TEM micrographs of deposits: (a) nickel, (b) cobalt.

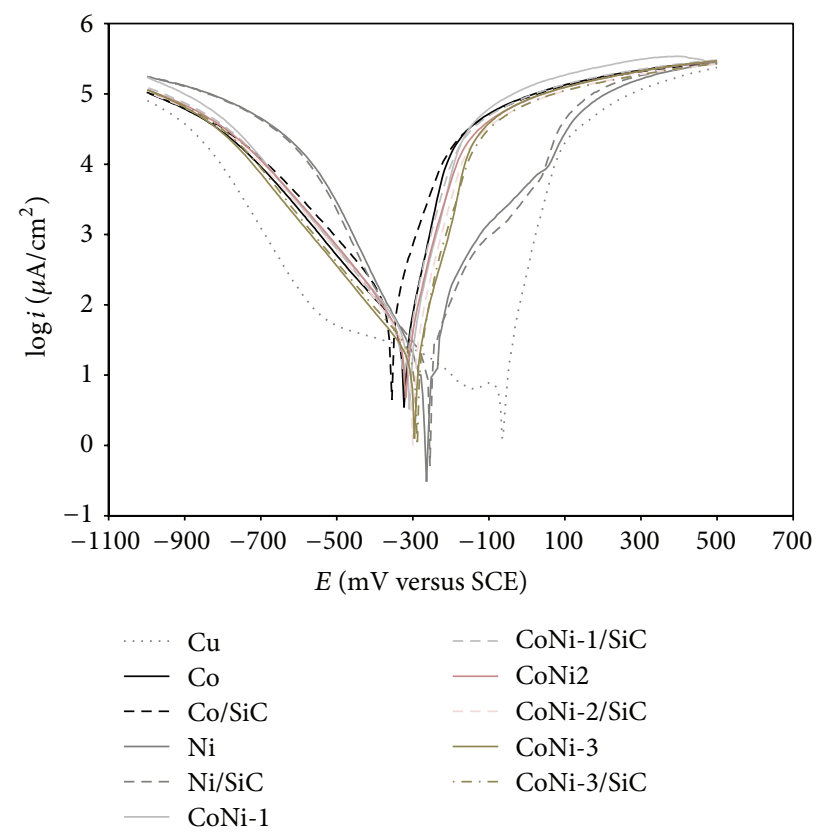

(a)

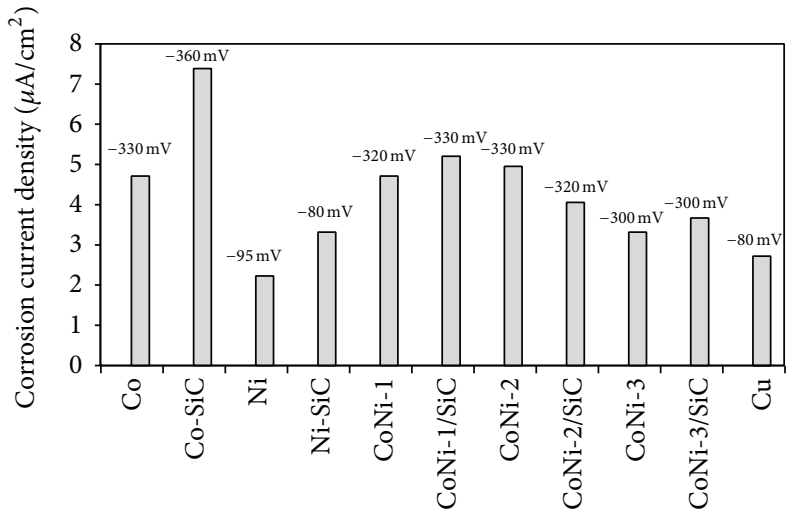

(b)

FIGURE 10: Corrosion resistance of deposits in $\mathrm{H}_{2} \mathrm{SO}_{4}$ : (a) polarization curves; (b) current densities and corrosion potentials.

suspended in the bath affect slightly the reduction of metallic ions. Incorporation of the ceramic particles was governed mainly by the morphology of the matrix surface, while no strict correlation between the amount of cobalt ions adsorbed on $\mathrm{SiC}$ and the $\mathrm{SiC}$ content in the composites was found. Higher mechanical entrapment of the particles was observed for cobalt-containing layers due to their high surface roughness. It seems that catalytic effect of cobalt ions on the particles codeposition can be found only for high nickel Co-Ni systems.

Microhardness of nickel deposits was almost twice higher than that for cobalt and Co-Ni alloys. Fine-grained nickel deposits were characterized by high corrosion resistance, but development of the surface roughness enhanced corrosion of the deposits. The presence of $\mathrm{SiC}$ in the matrix did not drastically affect the properties of the matrix, since low particles percentages were built in the metallic layers.

\section{Conflict of Interests}

The authors declare that there is no conflict of interests regarding the publication of this paper.

\section{References}

[1] F. C. Walsh and C. Ponce de Leon, "A review of the electrodeposition of metal matrix composite coatings by inclusion of particles in a metal layer: an established and diversifying technology," Transactions of the IMF, vol. 92, no. 2, pp. 83-98, 2014.

[2] C. T. J. Low, R. G. A. Wills, and F. C. Walsh, "Electrodeposition of composite coatings containing nanoparticles in a metal 
deposit," Surface and Coatings Technology, vol. 201, no. 1-2, pp. 371-383, 2006.

[3] I. Garcia, A. Conde, G. Langelaan, J. Fransaer, and J. P. Celis, "Improved corrosion resistance through microstructural modifications induced by codepositing $\mathrm{SiC}$-particles with electrolytic nickel," Corrosion Science, vol. 45, no. 6, pp. 1173-1189, 2003.

[4] A. Bund and D. Thiemig, "Influence of bath composition and $\mathrm{pH}$ on the electrocodeposition of alumina nanoparticles and nickel," Surface and Coatings Technology, vol. 201, no. 16-17, pp. 7092-7099, 2007.

[5] C. Cai, X. B. Zhu, G. Q. Zheng et al., "Electrodeposition and characterization of nano-structured Ni-SiC composite films," Surface and Coatings Technology, vol. 205, no. 11, pp. 3448-3454, 2011.

[6] H. K. Lee and J. Y. Jeon, "Codeposition of micro- and nano-sized $\mathrm{SiC}$ particles in the nickel matrix composite coatings obtained by electroplating," Surface and Coatings Technology, vol. 201, no. 8, pp. 4711-4717, 2007.

[7] B. J. Hwang and C. S. Hwang, "Mechanism of codeposition of silicon carbide with electrolytic cobalt," Journal of the Electrochemical Society, vol. 140, no. 4, pp. 979-984, 1993.

[8] G. Cârâc, A. Bund, and D. Thiemig, "Electrocodeposition and characterization of cobalt lanthanide oxides composite coatings," Surface and Coatings Technology, vol. 202, pp. 403411, 2007.

[9] G. N. K. Ramesh Bapu and T. Thiruchelvam, "Electrodeposited cobalt-boron nitride composites," Bulletin of Electrochemistry, vol. 17, no. 12, pp. 529-534, 2001.

[10] M. Srivastava Sr., V. K. W. Grips, A. Jain, and K. S. Rajam, "Influence of $\mathrm{SiC}$ particle size on the structure and tribological properties of Ni-Co composites," Surface and Coatings Technology, vol. 202, no. 2, pp. 310-318, 2007.

[11] G. Wu, N. Li, D. Zhou, and K. Mitsuo, "Electrodeposited Co$\mathrm{Ni}-\mathrm{Al}_{2} \mathrm{O}_{3}$ composite coatings," Surface and Coatings Technology, vol. 176, no. 2, pp. 157-164, 2004.

[12] B. Bahadormanesh, A. Dolati, and M. R. Ahmadi, "Electrodeposition and characterization of $\mathrm{Ni}-\mathrm{Co} / \mathrm{SiC}$ nanocomposite coatings," Journal of Alloys and Compounds, vol. 509, no. 39, pp. 9406-9412, 2011.

[13] X. Y. Yang, K.-J. Li, X. Peng, and F. H. Wang, "Beneficial effects of $\mathrm{Co}^{2+}$ on co-electrodeposited $\mathrm{Ni}$-SiC nanocomposite coating," Transactions of Nonferrous Metals Society of China, vol. 19, pp. 119-124, 2009.

[14] L. Burzyńska, E. Rudnik, J. Koza, L. Błaż, and W. Szymański, "Electrodeposition and heat treatment of nickel/silicon carbide composites," Surface and Coatings Technology, vol. 202, no. 12, pp. 2545-2556, 2008.

[15] E. Rudnik, L. Burzyńska, and M. Gut, "The effect of $\mathrm{Cs}^{+}$ions on codeposition of $\mathrm{SiC}$ particles with nickel," Materials Chemistry and Physics, vol. 126, pp. 573-579, 2011.

[16] E. Rudnik, L. Burzyńska, Ł. Dolasiński, and M. Misiak, "Electrodeposition of nickel/SiC composites in the presence of cetyltrimethylammonium bromide," Applied Surface Science, vol. 256, no. 24, pp. 7414-7420, 2010.

[17] E. Rudnik, L. Burzyńska, J. Jędruch, and L. Błaż, “Codeposition of $\mathrm{SiC}$ particles with electrolytic cobalt in the presence of $\mathrm{Cs}^{+}$ ions," Applied Surface Science, vol. 255, no. 16, pp. 7164-7171, 2009.

[18] E. Rudnik, L. Burzyńska, and M. Gębka, "Influence of CTAB cationic surfactant on codeposition of $\mathrm{SiC}$ particles with cobalt," Transactions of the Institute of Metal Finishing, vol. 89, no. 1, pp. 33-38, 2011.
[19] E. Rudnik, "Influence of $\mathrm{Cs}^{+}$ions on codeposition of $\mathrm{SiC}$ particles with Ni-Co alloy," Transactions of the Institute of Metal Finishing, vol. 87, no. 5, pp. 239-245, 2009.

[20] L. Shi, C. Sun, P. Gao, F. Zhou, and W. Liu, "Mechanical properties and wear and corrosion resistance of electrodeposited Ni$\mathrm{Co} / \mathrm{SiC}$ nanocomposite coating," Applied Surface Science, vol. 252, no. 10, pp. 3591-3599, 2006.

[21] M. R. Vaezi, S. K. Sadrnezhaad, and L. Nikzad, "Electrodeposition of Ni-SiC nano-composite coatings and evaluation of wear and corrosion resistance and electroplating characteristics," Colloids and Surfaces A: Physicochemical and Engineering Aspects, vol. 315, no. 1-3, pp. 176-182, 2008.

[22] S. C. Wang and W. C. J. Wei, "Kinetics of electroplating process of nano-sized ceramic particle/Ni composite," Materials Chemistry and Physics, vol. 78, pp. 574-580, 2003.

[23] A. Brenner, Electrodeposition of Alloys, vol. 1-2, Academic Press, London, UK, 1963.

[24] L. S. Čerović, S. K. Milonjić, M. B. Todorović et al., "Point of zero charge of different carbides," Colloids and Surfaces A, vol. 297, pp. 1-6, 2007.

[25] G. Vidrich, J.-F. Castagnet, and H. Ferkel, "Dispersion behavior of $\mathrm{Al}_{2} \mathrm{O}_{3}$ and $\mathrm{SiO} 2$ nanoparticles in nickel sulfamate plating baths of different compositions," Journal of the Electrochemical Society, vol. 152, no. 5, pp. C294-C297, 2005.

[26] A. Grosjean, M. Rezrazi, and M. Tachez, "Study of the surface charge of silicon carbide ( $\mathrm{SiC}$ ) particles for electroless composite deposits: Nickel-SiC," Surface and Coatings Technology, vol. 96, no. 2-3, pp. 300-304, 1997.

[27] G. Wu, N. Li, D. L. Wang, D. R. Zhou, B. Q. Xu, and K. Mitsuo, "Effect of $\alpha-\mathrm{Al}_{2} \mathrm{O}_{3}$ particles on the electrochemical codeposition of Co-Ni alloys from sulfamate electrolytes," Materials Chemistry and Physics, vol. 87, no. 2-3, pp. 411-419, 2004. 

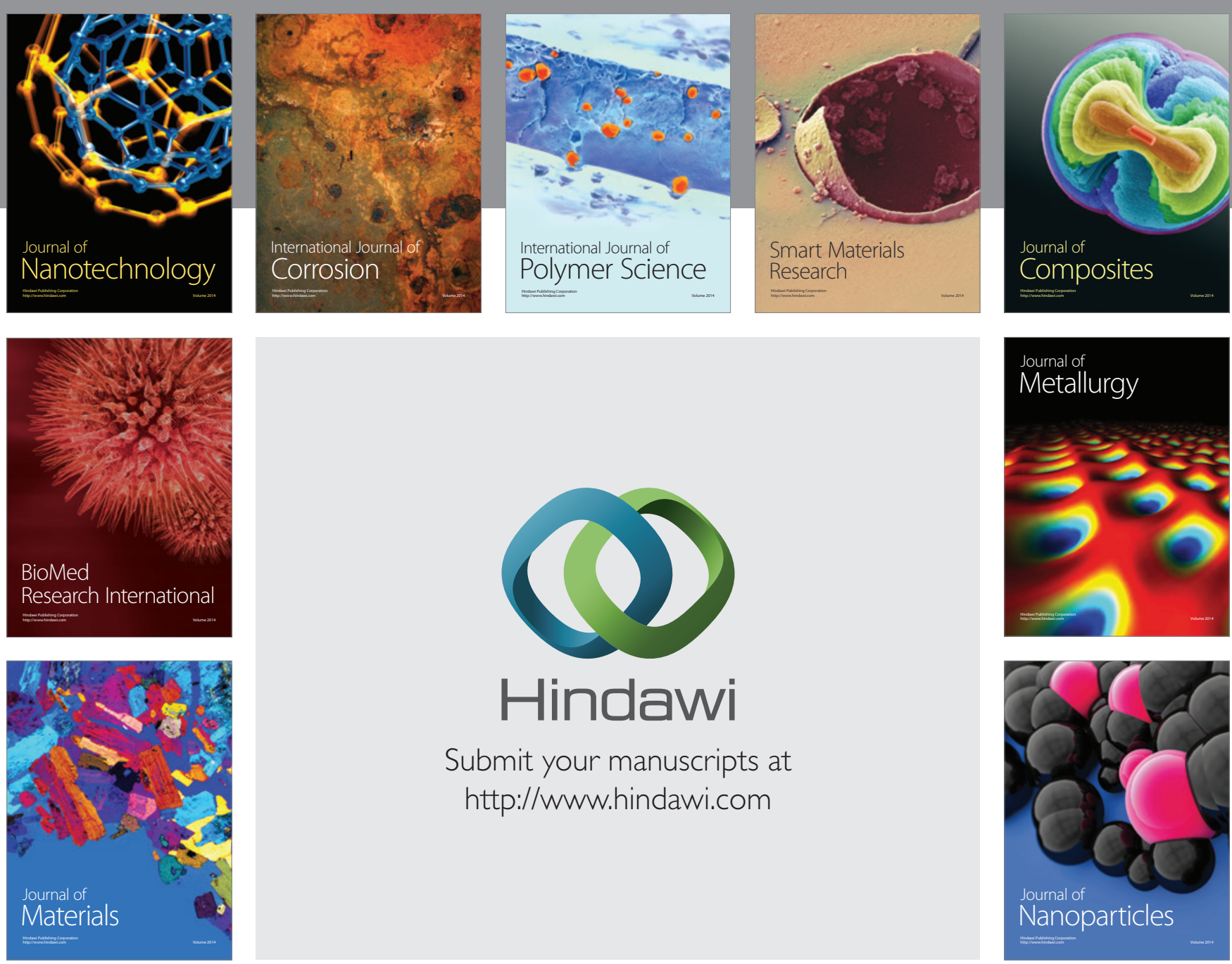

Submit your manuscripts at http://www.hindawi.com
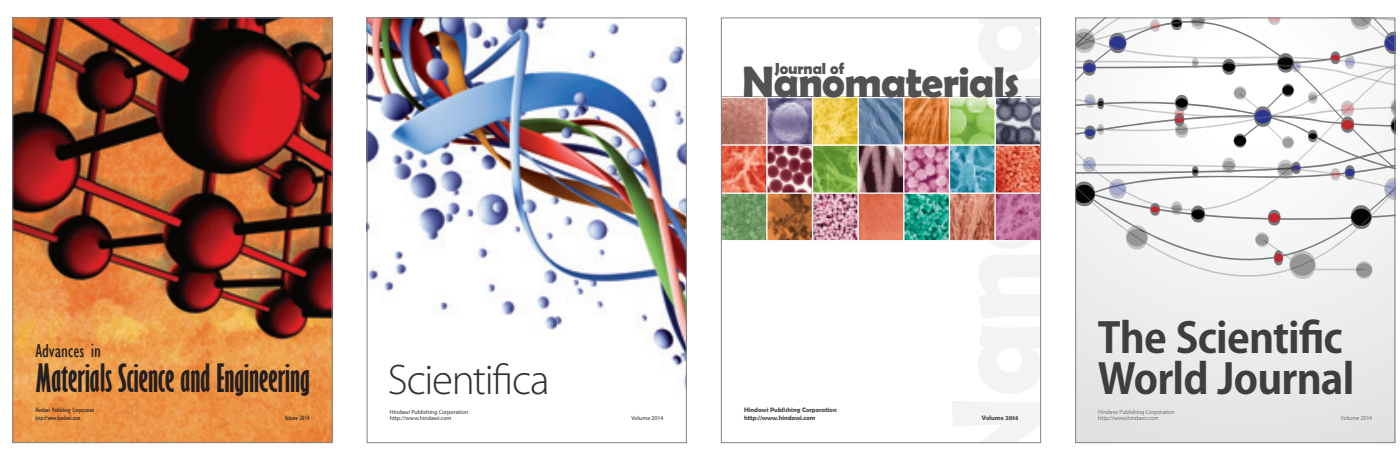

\section{The Scientific World Journal}
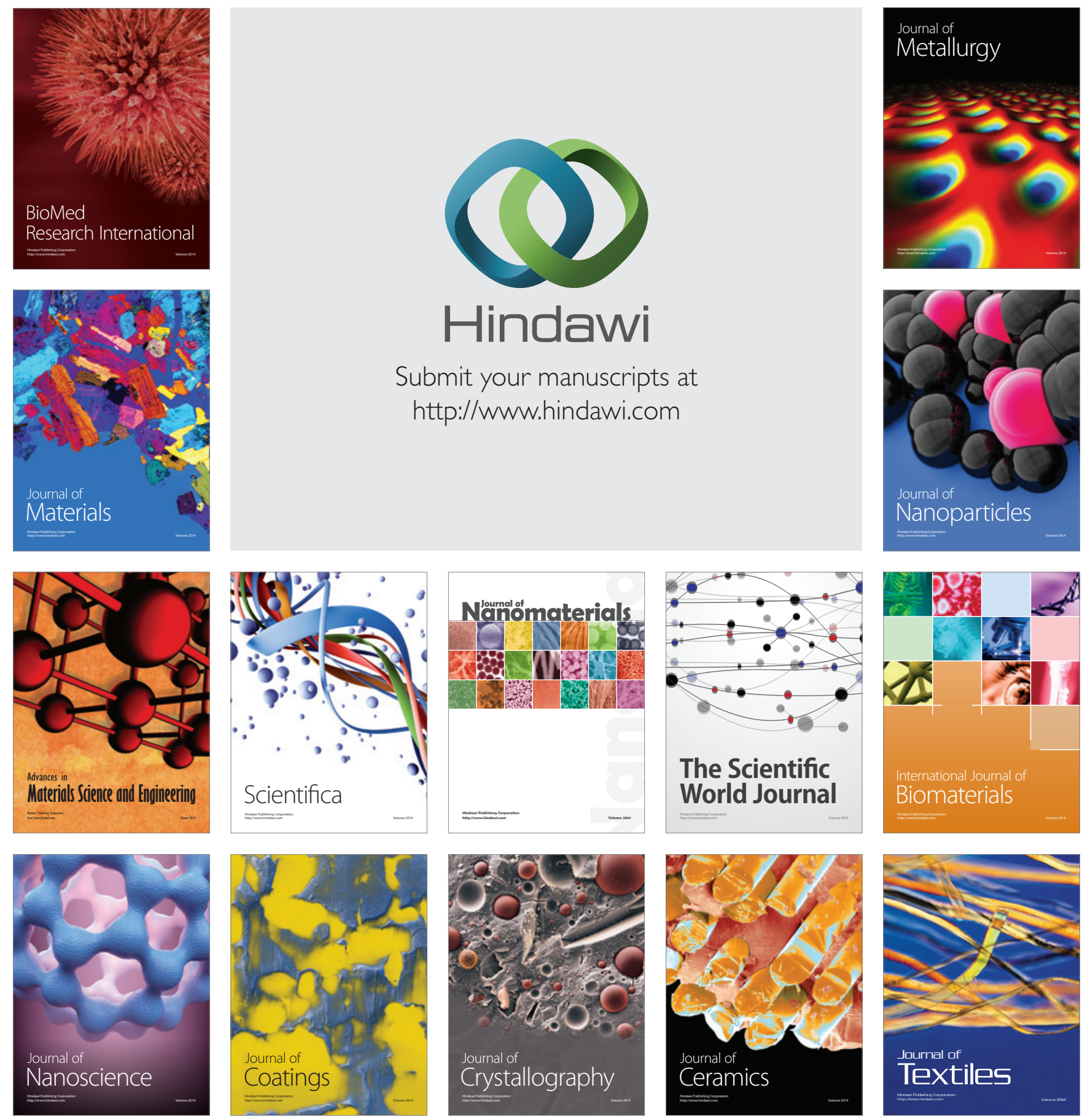